\title{
Sustainability Assessment of Alternatives for Heat Generation and Transfer in Saunas
}

\author{
Nora Munguia1,2, Luis Velazquez1,2, Rafael Perez1, Daniel Rincón1, Martha Marin1, \\ Biagio F. Giannetti ${ }^{3}$, Cecília M. V. B. Almeida ${ }^{3}$, Feni Agostinho ${ }^{3}$ \\ ${ }^{1}$ Sustainability Graduate Program, Industrial Engineering Department, University of Sonora (UNISON), \\ Hermosillo, Mexico \\ ${ }^{2}$ Work Environment Department, University of Massachusetts Lowell, Lowell, MA, USA \\ ${ }^{3}$ Production Engineering Graduate Program, Paulista University (UNIP), São Paulo, Brazil \\ Email: Luis_Velazquez@industrial.uson.mx
}

Received 18 November 2015; accepted 13 December 2015; published 17 December 2015

Copyright (C) 2015 by authors and Scientific Research Publishing Inc.

This work is licensed under the Creative Commons Attribution International License (CC BY).

http://creativecommons.org/licenses/by/4.0/

(c) (i) Open Access

\begin{abstract}
In the search for renewable energy sources, solar energy appears, among others, as a powerful alternative; mainly for those countries located at Earth's equatorial region. This is the case of a Fresnel device that uses solar radiation to warm-up the air; for instance, within saunas. Authors coined the term sustainable technological innovation to refer to a technological innovation in accordance to the principles of sustainability. The object of this research was comparing the sustainability of a Fresnel Lens Solar Concentration (FLSC) against the sustainability of other twelve alternatives to generate heat. This article assesses the sustainability of fourteen technological options for heat generation and transfer to saunas in the northwest region of Mexico where temperatures often reach above $45 \mathrm{C}$ and where there is a greater potential for exploiting solar energy. Emergy accounting, economic analysis, and global warming potential are the three indicators considered in quantifying sustainability. Results show that infrared ceramic photovoltaic, infrared carbon photovoltaic and infrared metal photovoltaic are the most sustainable systems. The Fresnel device reached the fourth and tenth position, using electricity from photovoltaic and from grid respectively, among all fourteen assessed devices, respectively. Although Fresnel equipment does not release any global warming gases into the atmosphere, or even it demands low amount of nonrenewable resources, 1.40 and $4.47 \mathrm{E17} \mathrm{seJ}_{\mathrm{F}} / \mathrm{yr}$. it requires high economic investment, 20,800 and 79,600 USD/yr, for the implementation and operation phases, which decrease its sustainability performance compared to twelve other evaluated devices.
\end{abstract}

\section{Keywords}

Emergy, Sustainable Technology Innovation, Heat Generation and Transfer, Saunas

How to cite this paper: Munguia, N., Velazquez, L., Perez, R., Rincón, D., Marin, M., Giannetti, B.F., Almeida, C.M.V.B. and Agostinho, F. (2015) Sustainability Assessment of Alternatives for Heat Generation and Transfer in Saunas. Journal of Environmental Protection, 6, 1378-1393. http://dx.doi.org/10.4236/jep.2015.612120 


\section{Introduction}

Sustainable development is a very broad term often used which refers to current global issues such as excessive population growth, increasing regional famine, social inequality, water and energy, climate change and natural resources depletion [1]. Although this term was coined long time ago in 1987 [2], there is still a lot of debate about its real meaning [3].

Taking into account that sustainable development is based on social, economic and environmental pillars [4], which may lead toward a human development in a responsible manner [5]; energy must undoubtedly be one of its main questions. In fact, ensuring energy supply without the resulting environmental impacts is one of the greatest challenges in this century [6].

A secure, reliable, affordable, clean and socially energy supply is necessary to an economic growth and human development [7]. However, most of the energy used nowadays is generated from non-renewable sources; by 2012, renewable energy constituted only $21 \%$ of the worldwide energy, although it is expected to increase to $33 \%$ by 2040 [8], [9]. Particularly in the case of Mexico, electricity generation relies heavily on the combustion of fossil fuels, $96 \%$ [10].

Renewable energy comes from sources that can be naturally replenished, this has a considerably lower impact on matters such as resource depletion and emissions when compared to traditional energy generation and consumption methodologies [11].

Solar energy has a huge potential to be used by society, since all energy available for use on Earth is direct or indirectly related to the sun [12]. This is particularly suitable along the Earth's Sunbelt close to the Earth's thermal equatorial region, which covers a vast amount of developing countries in central Africa and America [13], [14].

The potential of the solar energy systems has opened new markets for sustainable entrepreneurs that seek to develop environmental sound technologies and with this, the emergence of solar technologies that are usually driven by technological innovations. Technological innovation refers to changes in the functionalities of the product; often, the change is not observable because it is internal to the product form [15]. However, they can be an efficient means of avoiding the pollution associated with conventional energy generation processes [16].

In many cases, sustainability is the mother lode of technological innovation [5]. This type of innovation can be radical, at new product level, or incremental and process oriented [17]. Often, radical innovation occurs before incremental and process oriented innovation; this happened with solar concentrator technology that uses trackers with mirrors that follow the sun's path and concentrate its heat. Actually, the most utilized technological approaches for small-scale applications are parabolic trough (PTSC) and Fresnel linear (FLSC) solar concentrators; PTSC has the lead on the efficiency front [18]; on the other hand, FLSC might have had other advantages in terms of mechanical difficulties and operation and maintenance expenses [19].

In any case, a sustainability appraisal system is necessary to assess its performance in each of the sustainability dimensions [20]. The appraisal system must have precise indicators to provide operational information in order to analyze trends and cause-and-effect relationships [21]. A complete quantitative assessment is necessary when it comes to finding alternatives that bring development to a more sustainable state.

Regarding electricity generation, the green-house-gas (GHG) emissions per kWh of generated energy is considered a suitable parameter in defining the sustainability of the electricity system at different scales [22]. On the other hand, for a more grounded sustainable assessment, environmental considerations under a unique scale of analysis hardly will be enough to comprise all aspects related to a broader definition of sustainability [23].

As a complementary approach in quantifying electricity consumption to assess sustainability, the emergy method appears to be very useful [24]. This is grounded in thermodynamic laws and a donor side perspective in quantifying value, which allows for taking into account natural resource use rates, efficient exploitation and waste carrying capacity [25].

The object of this research was to compare the sustainability of a Fresnel Lens Solar Concentration (FLSC) against the sustainability of twelve other alternatives to generate heat.

\section{Methodology}

The FLSC is intended to be a technological innovation within a sustainable sauna that is being built at a sport facility located at Hermosillo, Sonora, Mexico; where temperatures often reach above $45 \mathrm{C}$ and where there is a greater potential for exploiting solar energy [26]. 
The sauna bathroom measures 2.3 by 1.8 meters with a total area of $4.15 \mathrm{~m}^{2}$ and a height of 2.1 meters. The total internal volume accounts for $8.69 \mathrm{~m}^{3}$. When in operation, the sauna is going to require a temperature of $75^{\circ} \mathrm{C}$ for a capacity for up eight users. Sustainability was measured by means of the emergy accounting method, by an economic analysis, and by their global warming potential. More information on these methods is provided on the following sections.

\subsection{Case Study}

The premise of innovation is reinventing the means for completion of known goals, with existing knowledge and inputs recombined to enhance either the procedure itself or the resulting product as a new valuable output [27]. Innovation can take the form of a utility model that describes the capacity to improve a device, based on marginal modifications. Usually, utility models have the potential for industrial application [28]. In developing countries, like Mexico, the utility model is recognized as a major constituent of environmentally related innovation [29].

For the purpose of this case study, authors coined the term sustainable technological innovation (STI) to refer to a technological innovation in accordance with the principles of sustainability. Traditionally, saunas use gas or electricity for heat generation; therefore, the use of solar energy would be a sustainable technological innovation (STI) that takes advantage of a renewable energy source. The main idea behind the STI is integrating the FLSC as a subsystem to the entire ecological environment of the sauna; taking into account that the natural environment offers the conditions for the development of sports in harmony with nature [30]. Solar thermal concentration techniques at small scale have been already tested [31].

Demonstrating its technical feasibility was not enough, for that reason, it was necessary to contrast the FLSC, in sustainability terms, against other heating alternatives. Figure 1 shows the heat sources considered in this research because they are the most widely adopted and sold in the market.

\subsection{A Sustainability Assessment Model}

According to [33], ever since the use of thermodynamics in explaining ecosystem functioning, plenty of attention has been given to the cause-effect relation integrating input, state, and output for an evaluated system. Generally, it is an open system where only matter and energy inputs are necessary to build and sustain the system's

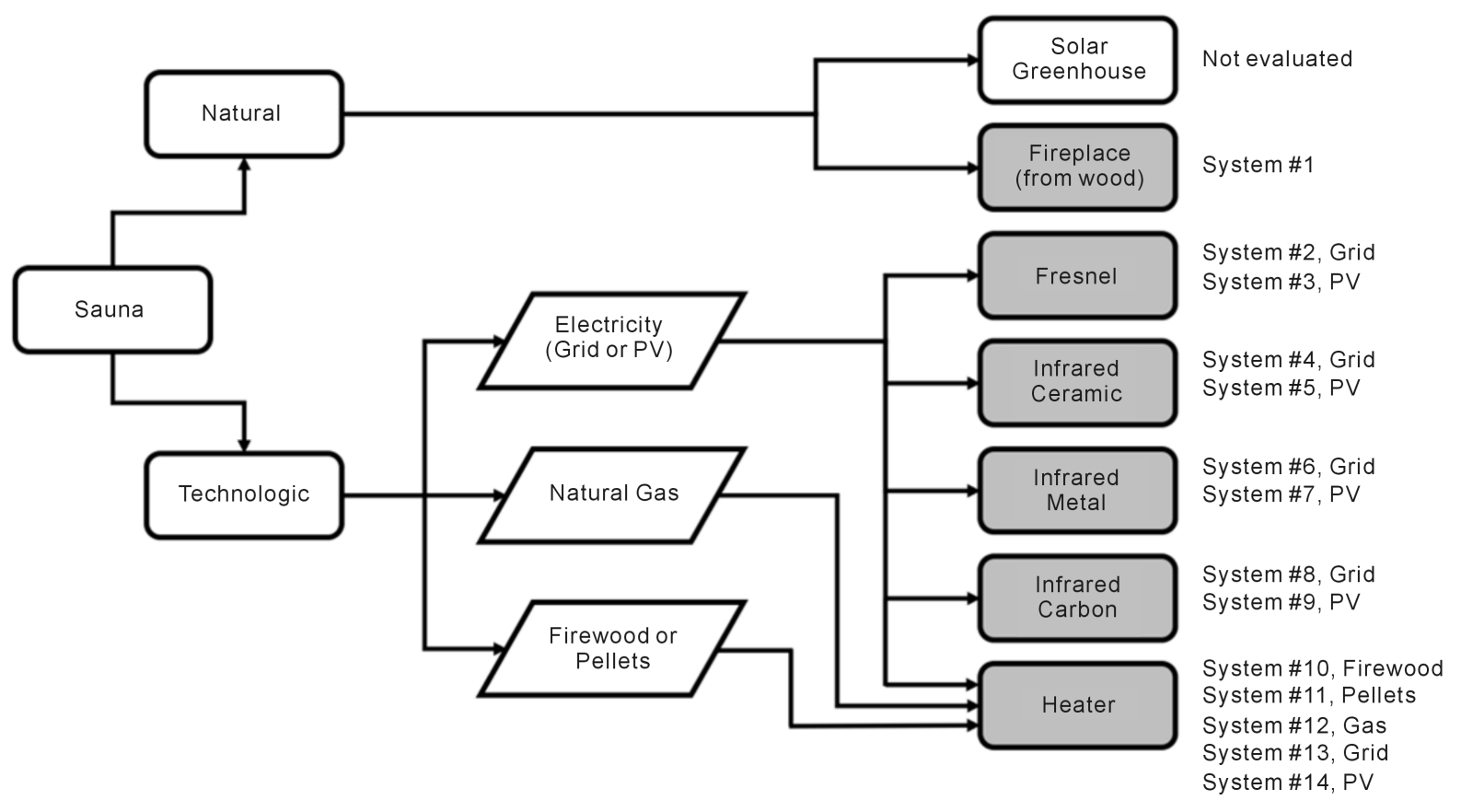

Figure 1. Heat source classification according to its origin, adapted from [32]. Gray rectangles indicate the alternatives technologies assessed in this study considering their different heat sources. 
functionality, including the internal structure, towards maximizing the conversion of energy and matter inputs into useful services and goods outputs.

The model on Figure 2 illustrates the representation of a production system, since its objective is using efficiently all system inputs from renewable resources by converting them into a network that maximizes production, which results in lower amounts of waste as output.

In relation to the "input", the importance in quantity and quality of the resources as key elements on the system's development is of recognition, where the use of environmental Emergy accounting [24] is noteworthy when compared to other approaches due to its systemic character, a donor side view in establishing value, and the recognition of energy quality. According to [33], although not having a strong anthropocentric relation with systems output, the use of Emergy on the "input" representation denotes a biophysical counterpart for this "output"; which then stands for the importance of environmental work, true wealth, needed for human action and acquisition of wellbeing. In this study, the non-renewable Emergy coming from economy "F" used by the system is considered an indicator for the distance between the system itself and sustainability. It means that higher system dependence on " $F$ " resources translates to higher distance to sustainability, because by definition "F" resources are classified as non-renewable resources.

For the "state" aspect, [34] argue that an economy's operation is based on the conversion from resources into goods and services useful to society; usually monetary value. Given the recognized importance and influence on decision making, monetary cost of implementing and maintaining the functioning of studied systems is considered a measure of "state".

As a measure of output, among several other alternatives, the global warming potential (GWP) indicator is being widely used and recognized as important due to climate change concerns around the world. In this sense, this work assumes that GWP is considered as representative for the "output" for the sustainability model adopted. For this purpose, the direct emissions of $\mathrm{CO}_{2}, \mathrm{CH}_{4}$ and $\mathrm{NO}_{2}$ are accounted for as byproducts of the energy generation process supplying heat for the devices in Saunas.

Deeper details on the emergy accounting and economic approaches, as well as GWP indicator calculations used in this work are presented in the following sections.

\subsubsection{Emergy Accounting}

Emergy Accounting evaluates the environmental performance of the system on a global scale, accounting for all considered "free" environmental resources such as sunlight, wind, rain, soil, and the indirect environmental support embodied in human labor and services. This methodology has been used previously for decision making allowing efficient resource usage [35] since it considers the studied system's energy flows [36] by integrating both a human and natural economies [37].

The accounting is extended back in time to include the environmental work needed for resource formation, thus emergy is a measure of the past and present environmental support to any process occurring in the biosphere [38]. According to the second law of classic thermodynamics, each transformation process degrades the available potential energy while the "quality" of the remaining energy in the product is increased. Energy quality is crucial when discussing emergy accounting, as expressed by the Emergy Intensity Values ${ }^{1}$.

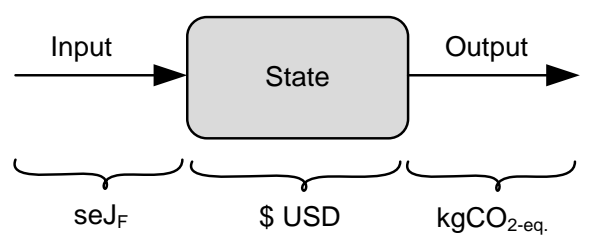

Figure 2. Representation for the input-state-output model of a production system. Adapted from [34]. Legend: $\mathrm{seJ}_{\mathrm{F}}=$ solar emjoules, a unit measure of emergy method; $\mathrm{kgCO}_{2 \text {-eq. }}=$ kilograms of carbon dioxide equivalent, an indicator of global warming potential.

\footnotetext{
${ }^{1}$ Emergy Intensity Value (also called the Unit Emergy Value-UEV) represents all emergy used to make a unit of product. The definition of Emergy Intensity is very similar to that of Energy Intensity (used in Energy Analysis), but Emergy Intensity accounts for more than only market energy. One of the most important UEV is denominated Transformity, and it represents the amount of emergy that was originally required to provide one Joule of a good or service (units in solar emjoules per joule, seJ/J). Other UEVs are: Specific Emergy (seJ/g), Emergy per Monetary Unit (seJ/\$; usually expressed as seJ/USD) and Emergy per Unit Labor (seJ/h; the amount of emergy supporting one hour of human labor).
} 
Emergy accounting is organized as a top down approach. For its application, initially an energy system diagram using the symbols, proposed by [24] must represent the system under study. Subsequently, all raw values of energy and mass going into the system are multiplied by their respective emergy intensity values, resulting in flows represented with the same unit: solar emjoules (seJ). Finally, these flows are aggregated to calculate the emergy indices to draw conclusions about the system's sustainability performance. Deeper understanding about Emergy Accounting rules, meanings and calculation procedure can be found mainly at [24] and [38].

Usually, the indices considered in emergy studies, shown in Figure 3, are UEV, Renewability (\%R), Emergy Yield Ratio (EYR), Environmental Loading Ratio (ELR) and Sustainability Index (ESI), but sustainability in this analysis was characterized by the lowest possible dependency of resources from economy, usually labeled as non-renewable. Thus, the emergy indicator used to represent sustainability in this work is "F", i.e. the feedback from economy resources representing the sum of materials, energy, services and labor used by each individual heat supplier evaluated.

The feedback from economy indicator ("F") was obtained by multiplying the raw data as presented in Appendix B by its respective Unit Emergy Value as presented in Appendix A and by its respective partial renewability as presented in Appendix B.

\subsubsection{Economic Cost}

Economic cost represents the market cost during implementation and maintenance phases for all 14 analyzed systems during a 20-year lifetime. After elaborating a database containing the quantitative amount of materials and services demanded for construction and maintenance of each heat system, the market values of each input into the system boundaries were obtained from regular market for the Mexican case in 2014. The Mexican currency values, Mexican pesos, were converted to US dollars because it represents an international currency; for this, a conversion rate of $13.10 \mathrm{MXN} / \mathrm{USD}$ was used. All economic values are presented in Appendix B.

\subsubsection{Direct Emissions}

Emissions can be accounted for as direct (or local) and indirect (or global), according to different scales of analysis. In this regard, see for instance [39]. For the purposes of this work, only the direct emissions are considered to evaluate the related emissions in using a particular energy source to obtain heat within sauna. For this, the following emission factors from [40] are considered: 1) wood and wood residuals $=1640 \mathrm{kgCO}_{2} / \mathrm{ton}, 126$ $\mathrm{gCH}_{4} /$ ton, and $63 \mathrm{gN}_{2} \mathrm{O} / \mathrm{ton}$; 2) gas fuel $=7.76 \mathrm{E}-8 \mathrm{kgCO}_{2} / \mathrm{J}$, 3.94E $-9 \mathrm{gCH}_{4} / \mathrm{J}$, and $7.89 \mathrm{E}-10 \mathrm{gN}_{2} \mathrm{O} / \mathrm{J}$. To calculate the global warming potential (GWP) indicators, a 100-year time interval for impacts is considered under the following weight factors: 1) $\mathrm{CO}_{2}=1$; 2) $\mathrm{CH}_{4}=25$; 3) $\mathrm{N}_{2} \mathrm{O}=298$.

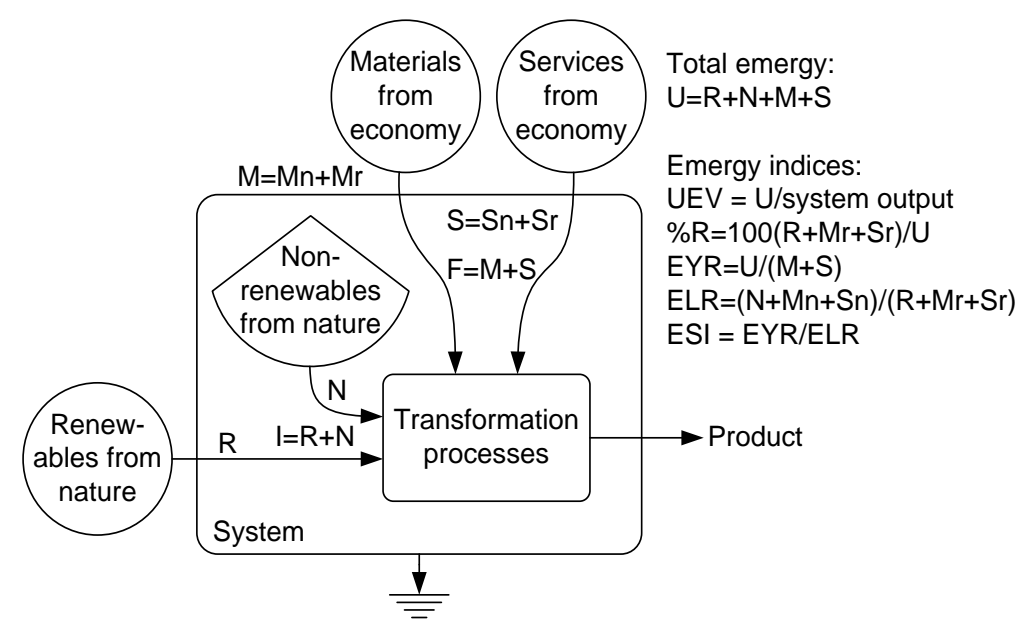

Figure 3. Generic energy diagram representing all energy sources involved in the transformation process. Symbols from [24]. Suffixes " $n$ " and "r" stand for nonrenewable and renewable respectively, referring to the renewable and nonrenewable component of material and energy flows. 


\subsection{Graphical Representation of Results}

Aiming to improve their interpretation, results are presented on a graphical design. All fourteen systems are plotted in the same graph, and for this, a linear normalization is considered to allow that all indicators ranges from zero (minimum value) to one (maximum value). This is done by setting the maximum value achieved by the highest rated system for a specific indicator to 1 , while the lowest possible value is set to 0 . Then, a linear proportion is used for all others indicators to make them comparable. The approach chosen provides two important pieces of information: 1) the hierarchy from better to worst system performance according to the three indicators of sustainability considered in this work; 2) the area obtained for each system by taking into account all three indicators represents the overall sustainability of that system, where a large area indicates worst comparable performance.

\section{Results and Discussion}

The energy diagrams of Figure 4 and Figure 5 show, through the use of a systemic perspective, all material and energy system's inputs, internal relations, as well as the air heating outputs for the evaluated saunas. Due to similarity between some systems functioning, two representative diagrams were drawn by merging the electric heat source alternatives, including Fresnel, infrared ceramic, metal, carbon, and heater, in one diagram, while the other one represents firewood, pellets and gas technological options. The energy diagrams are representative models of reality as interpreted by the authors. One objective for these energy diagrams is to allow the reader a large-scale view, which can be considered useful to better understand the system's functioning and potentials for improvement. Through these diagrams, both analysts and readers can understand the needed embodied energy by the systems to produce a good or service, even recognizing the importance of the so-called hidden energy flows that are usually disregarded from several sustainability analyses due to methodological constraints or also due to a lack of large-scale comprehension about the worldwide energy relationship.

Both energy diagrams provide information regarding the demand for external resources (indicated by circle components) and labor. Additionally, it can be seen how these external resources interact within systems boundaries to produce a good or service, which are the warmed air to sauna and the sub-products as waste and emissions.

After understanding the systems functioning including their dependence on external resources as well as their internal framework, the three methodologies considered in this work as representative of sustainability were applied. Table 1 shows the three indicators obtained for the all fourteen assessed saunas heat sources. A high

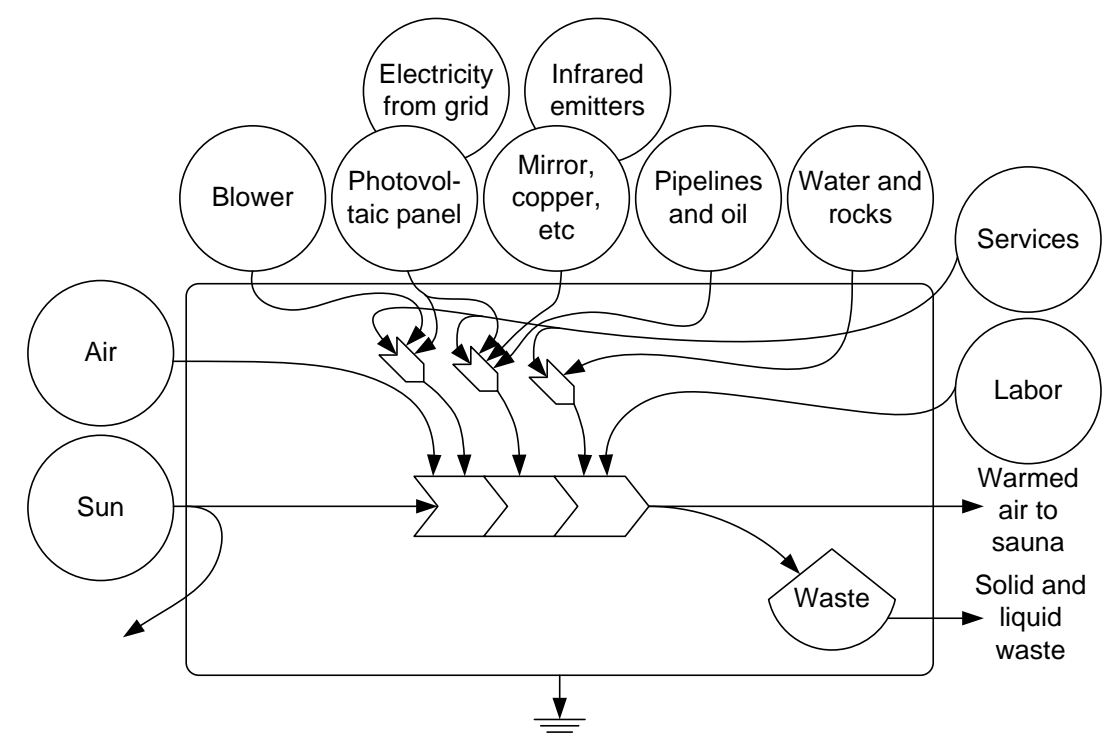

Figure 4. Energy diagram of electric alternatives for heat source. It includes Fresnel, infrared ceramic, metal, carbon and heater evaluated systems as previously shown in Figure 1. 


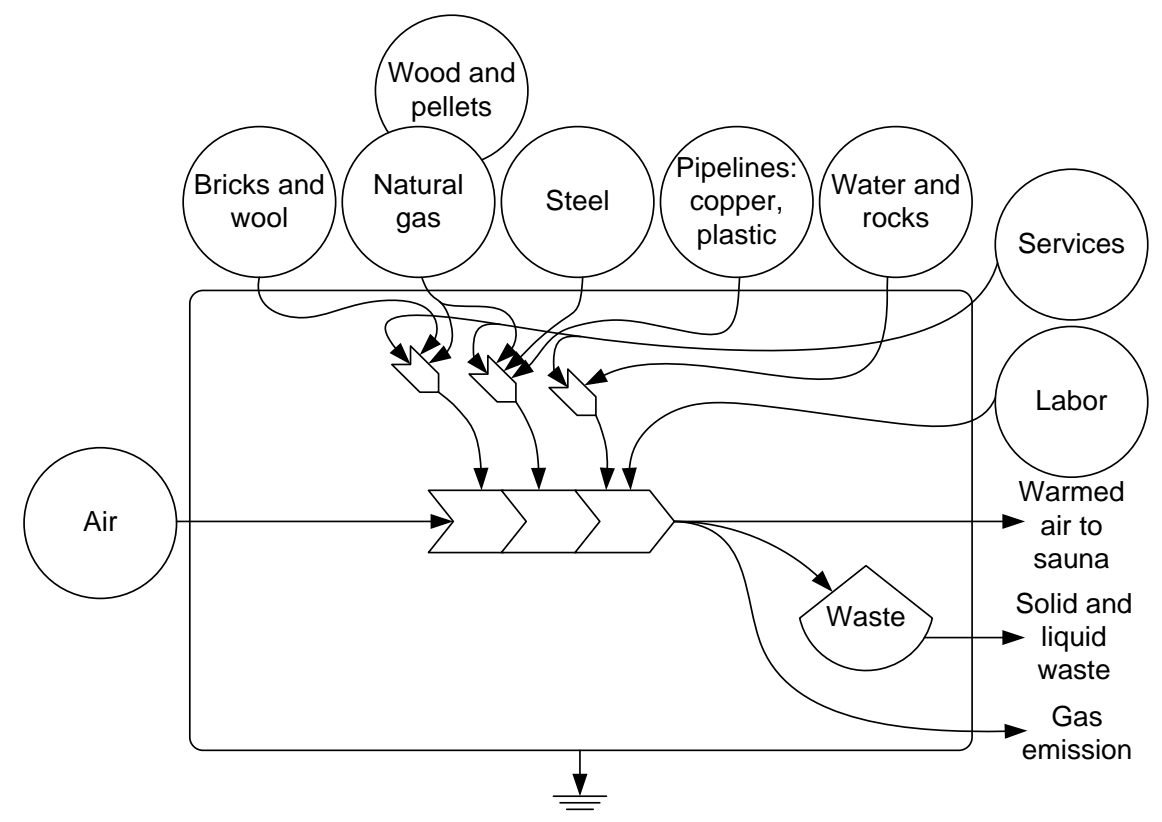

Figure 5. Energy diagram of heat sources from natural gas and vegetal biomass burning. It includes heater (firewood, pellets, and gas) and fireplace from wood, as previously shown in Figure 1.

Table 1. Emergy, economic and emission flow analyses for the fourteen assessed heat suppliers. Values correspond to a 20year lifetime per heater, including implementation and operation phases.

\begin{tabular}{|c|c|c|c|}
\hline System & $\begin{array}{l}\text { Emergy from economic resources } \\
\text { "F" in E17 seJ } / \mathrm{yr}^{\mathrm{a}}{ }^{\mathrm{a}}\end{array}$ & Economic costs in USD/yr. & $\begin{array}{l}\text { Global warming potential } \\
\text { in ton } \mathrm{CO}_{2 \text {-eq. }} / \mathrm{yr}^{\mathrm{c}}\end{array}$ \\
\hline \#1 Fireplace from wood & 9.74 & 105,000 & 1880 \\
\hline \#2 Fresnel grid & 4.47 & 79,600 & 0 \\
\hline \#3 Fresnel phot. & 1.40 & 20,800 & 0 \\
\hline \#4 Infrared ceramic grid & 5.75 & 44,100 & 0 \\
\hline \#5 Infrared ceramic phot. & 1.59 & 5420 & 0 \\
\hline \#6 Infrared metal grid & 5.76 & 44,100 & 0 \\
\hline \#7 Infrared metal phot. & 1.60 & 5420 & 0 \\
\hline \#8 Infrared carbon grid & 5.57 & 44,100 & 0 \\
\hline \#9 Infrared carbon phot. & 1.59 & 5420 & 0 \\
\hline \#10 Heater firewood & 19.00 & 57,300 & 831 \\
\hline \#11 Heater pellet & 6.14 & 25,600 & 23 \\
\hline \#12 Heater gas & 257.00 & 46,300 & 16,900 \\
\hline \#13 Heater grid & 18.30 & 204,000 & 0 \\
\hline \#14 Heater phot. & 6.71 & 78,900 & 0 \\
\hline
\end{tabular}

phot. = electricity from photovoltaic panels; ${ }^{\mathrm{a}} \mathrm{SeJ}_{\mathrm{F}} / \mathrm{yr}=$ (numbers from category column in Appendix B) $\times($ UEVs presented in Appendix A) $\times(1$-Partial renewability); ${ }^{\mathrm{b}}$ Economic costs available at Appendix B; GWP calculated by using raw data of Appendix B and coefficients presented in the previously "2.2.3. Direct emissions” section. 
amount of non-renewable resources "F" is demanded by system \#12 gas heater (257.00 $\left.\mathrm{E} 17 \operatorname{seJ}_{\mathrm{F}} / \mathrm{yr}\right)$, which represents about 10 times that of the second worst performance obtained by system \#10 firewood heater (19.00 E17 seJ $\mathrm{F}_{\mathrm{F}} / \mathrm{yr}$ ), followed by system \#13 heater grid (18.30 $\left.\mathrm{E} 17 \mathrm{seJ}_{\mathrm{F}} / \mathrm{yr}\right)$. This is a very interesting result because it was not expected since the economic cost of heater gas and firewood are not the most expensive devices. On the other hand, as emergy methodology considers a large-scale approach in its framework calculation, it means that both heaters (gas and firewood) demand indirectly, and usually not marketable, a large amount of global resources which implies in higher emergy for them. Due to this kind of result, the use of a multi-criteria approach instead of unique indicators to represent sustainability can be considered as more appropriate. All other systems demand non-renewable resources ranging from 1.40 to 9.74 E17 seJF/yr, placing systems \#3 Fresnel photovoltaic, \#5 infrared ceramic photovoltaic and \#7 infrared metal photovoltaic as the best performers for this particular sustainability indicator.

Different results were obtained when considering economic costs, in which case the worst performance was obtained by systems \#13 heater grid with 204,000 USD/yr, followed by systems \#1 fireplace from wood, \#2 Fresnel grid, and \#14 photovoltaic heater. For all other systems, the economic cost ranges from about 5,000 to 57,000 USD/yr, in which systems \#5 infrared ceramic photovoltaic and \#9 infrared carbon photovoltaic have the best overall performance with 5420 USD/yr.

Under this criterion, currency, only those resources that have market value are accounted for and valuated under an anthropocentric approach as willing-to-pay. Thus, free-of-charge resources are disregarded in the evaluation, and some are undervalued compared to an emergy perspective. For example, while natural gas or wood energy can reach high values under an emergy view, i.e. high transformity, their market value can be seen as low due to governmental subsidies. Emergy method does not allow this kind of subjectivity. Due to this main difference in the scientific bases for both metrics, results are also different when comparing economic versus emergy methods.

The third sustainability indicator considered in this work expressed by Global Warming Potential (GWP) showed that systems from \#2 to 9, \#13 and \#14 are not $\mathrm{CO}_{2}$ emitters-at least not at local scale as considered in this work-, thus those systems have the best performance for GWP. This behavior was already expected since the energy source supporting these systems comes from electricity (grid or photovoltaic) and not from burning vegetal biomass or fossil fuel-natural gas in this case. The worst performance was obtained by systems \#12 gas

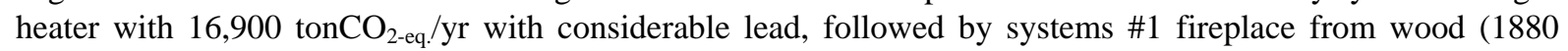

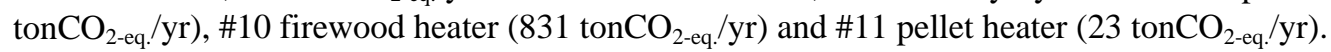

It is interesting to highlight that, according to Table 1, systems \#5 infrared ceramic photovoltaic, \#9 infrared carbon photovoltaic, and \#7 infrared metal photovoltaic have the best performance for all three indicators of sustainability considered in this work, resulting in the first position for them regarding sustainability when comparing all the fourteen systems evaluated. This is graphically expressed by Figure 6, which shows a normalization of all indicators provided in Table 1 for all fourteen analyzed systems. In this figure, systems are positioned in a sequence from better to worst general performances, where a larger area means worst overall performance considering all three indicators of sustainability at the same time. System \#12 gas heater had the largest area and consequently the worst sustainability performance compared to all other systems. This occurs because, although system \#12 has a moderate economic cost (46,300 USD/yr; occupying the ninth position among all systems), it has by far the highest GWP and dependence on non-renewable resources.

It is recognized that a sustainability assessment could include several other indicators under different scales and time approach aiming towards a multi-criteria perspective. However, the conceptual model considered in this work covers important biophysical and economic aspects strongly related to sustainability assessments, mainly for case studies under a very small-scale of attention as those ones evaluated in this work. Changes in the result data treatment from a linear normalization to a pondered scheme could be done to allow other interpretations.

Another interpretation on results could modify the performance outcome for each heating supply system; however, a subjective aspect would appear in weighting indicators, which is a non-recommended approach by several life cycle assessment analysts. As elicited by Figure 6, the differences between the acclaimed top performers are virtually negligible. In this sense, beyond showing the systems with better performance, results showed that systems \#12 and \#13, gas and grid heaters, had so far the worst performance for sustainability among the fourteen heat sources considered, thus both should not be chosen for future projects in Saunas. 


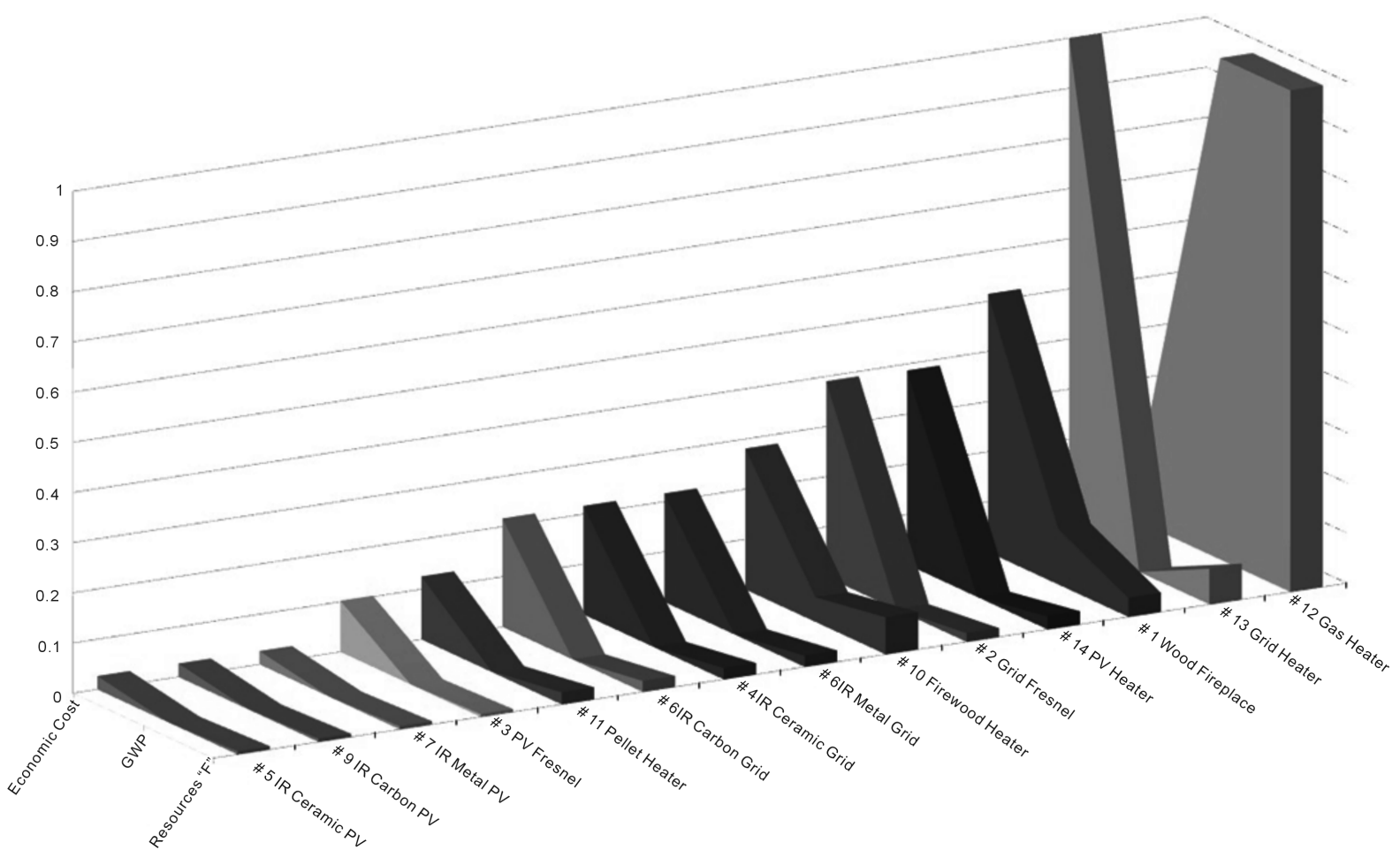

Figure 6. Graphical representation in decreasing sequence of sustainability performance for the fourteen heat generation systems studied. Larger area means lower sustainability according to the evaluation criteria used in this work.

\section{Conclusions}

Considering the methodological approaches and assumptions made in this work, the following conclusions can be drawn:

1) The evaluated systems \#5, \#9, and \#7, infrared ceramic photovoltaic, infrared carbon photovoltaic, and infrared metal photovoltaic, can be considered the most sustainable among all fourteen heat sources evaluated in this work, because they had the lowest economic cost, 5420 USD/yr, the absence of gas emissions causing global warming potential, and they demanded lower amount of non-renewable resources for their implementation and functioning, 1.59E17 seJ $\mathrm{F} / \mathrm{yr}$;

2) The Fresnel equipment, originally alleged to be the most sustainable one, reached the fourth and tenth positions, for electricity from photovoltaic and grid, systems \#3 and \#2 respectively, on the established sustainability hierarchy among all heat sources evaluated. Neither the absence of global warming potential nor their comparative low demand for non-renewable resources, 1.40 and $4.47 \mathrm{E} 17 \mathrm{seJ}_{\mathrm{F}} / \mathrm{yr}$, was able to classify them as the best systems, because they require high investment and maintenance economic costs, 20,800 and 79,600 USD/yr respectively.

\section{Acknowledgements}

Authors are grateful for financial support from Vice-President of the Post-Graduate and Research Department of the Paulista University in Brazil and the National Council for Science and Technology (CONACYT) in Mexico. This publication was supported by the fund OP/PROFOCIE-2014-26MSU0015Z-12-01.

\section{References}

[1] United Nations Development Programme (UNDP) (2013) Annual Report 2013—Supporting Global Process. UNDP, New York.

[2] World Commission on Environment and Development (WCED) (1987) Our Common Future. Oxford University Press, Oxford. 
[3] Drexhage, J. and Murphy, D. (2010) Sustainable Development: From Brundtland to Rio 2012. In: United Nations Headquarters, 1st Meeting by the High Level Panel on Global Sustainability, United Nations, New York.

[4] Hassan, A.M. and Lee, H. (2015) The Paradox of the Sustainable City: Definitions and Examples. Environment, Development and Sustainability, 17, 1267-1285. http://dx.doi.org/10.1007/s10668-014-9604-z

[5] Nidumolu, R., Prahalad, C.K. and Rangaswami, M.R. (2009) Why Sustainability Is Now the Key Driver of Innovation. Harvard Business Review, September Issue, 57-64.

[6] Allouhi, A., El Fouih, Y., Kousksou, T., Jamil, A., Zeraouli, Y., and Mourad, Y. (2015) Energy Consumption and Efficiency in Buildings: Current Status and Future Trends. Journal of Cleaner Production, in Press, 1-13.

[7] World Energy Council (WEC) (2013) World Energy Insight 2013. WCE, Daegu.

[8] International Renewable Energies Agency (IRENA) (2015) Renewable Energy Capacity Statistics 2015. http://www.irena.org/DocumentDownloads/Publications/IRENA_RE_Capacity_Statistics_2015.pdf

[9] International Energy Agency (IEA) (2014) World Energy Outlook 2014 Factsheet. http://www.worldenergyoutlook.org/media/weowebsite/2014/WEO2014FactSheets.pdf

[10] International Renewable Energies Agency (IRENA) (2015) Renewable Energy Prospects: Mexico. http://www.irena.org/DocumentDownloads/Publications/IRENA_REmap_Mexico_report_2015.pdf

[11] Intergovernmental Panel on Climate Change (IPCC) (2012) Renewable Energy Sources and Climate Change Mitigation. https://www.ipcc.ch/pdf/special-reports/srren/SRREN_FD_SPM_final.pdf

[12] Ismail, Z. (2011) Opportunities for Further Renewable Energy Utilization in Malaysia. International Journal of Energy Science, 1, 144-150.

[13] United Nations Development Programme (UNDP) (2010) Energy Poverty: How to Make Modern Energy Access Universal? OECD/IEA, Paris.

[14] World Alliance for Decentralized Energy (WADE) (2006) World Survey of Decentralized Energy 2006. WADE, Edinburgh.

[15] Griffith, D.A. and Rubera, G. (2014) A Cross-Cultural Investigation of New Product Strategies for Technological and Design Innovations. Journal of International Marketing, 22, 5-20. http://dx.doi.org/10.1509/jim.13.0082

[16] McElroy, M.B. (2010) Energy: Perspectives, Problems, and Prospects. Oxford University Press, Oxford.

[17] Eisenman, M. (2013) Understating Aesthetic Innovation in the Context of Technological Evolution. Academy of Management Review, 38, 332-351. http://dx.doi.org/10.5465/amr.2011.0262

[18] Wirz, M., Petit, J., Haselbacher, A. and Steinfield, A. (2014) Potential Improvements in the Optical and Thermal Efficiencies of Parabolic Trough Concentrators. Solar Energy, 107, 398-414. http://dx.doi.org/10.1016/j.solener.2014.05.002

[19] Zhu, G., Wendelin, T., Wagner, M.J. and Kutscher, C. (2014) History, Current State, and Future of Linear Fresnel Concentrating Solar Collectors. Solar Energy, 103, 639-652. http://dx.doi.org/10.1016/j.solener.2013.05.021

[20] Eales, R. and Sheatey, W. (2011) Effectiveness of Policy Level Environmental and Sustainability Assessment: Challenges and Lessons from Recent Practices. Journal of Environmental Assessment Policy and Management, 13, 39-65. http://dx.doi.org/10.1142/S146433321100378X

[21] Vasela, V. and Ellenbecker, M. (2001) Indicators of Sustainable Production: Framework and Methodology. Journal of Cleaner Production, 9, 519-549. http://dx.doi.org/10.1016/S0959-6526(01)00010-5

[22] Urbina, A. (2014) Solar Electricity in a Changing Environment: The Case of Spain. Renewable Energy, 68, $264-269$. http://dx.doi.org/10.1016/j.renene.2014.02.005

[23] Haapala, K.R., Zhao, F., Camelio, J., Sutherland, J.W., Skerlos, S.J., Dornfeld, D.A., Jawahir, I.S., Clarens, A.F. and Rickli, J.L. (2013) A Review of Engineering Research in Sustainable Manufacturing. Journal of Manufacturing Science and Engineering, 135, Article ID: 041013. http://dx.doi.org/10.1115/1.4024040

[24] Odum, H.T. (1996) Environmental Accounting: EMERGY and Environmental Decision Making. Wiley, New York.

[25] Giannetti, B.F., Barrella, F.A. and Almeida, C.M.V.B. (2006) A Combined Tool for Environmental Scientists and Decision Makers: Ternary Diagrams and Emergy Accounting. Journal of Cleaner Production, 14, 201-210. http://dx.doi.org/10.1016/j.jclepro.2004.09.002

[26] Woodrow Wilson International Center for Scholars (WWICS) (2012) Solar Energy Potential in Mexico’s Northern Border States. WWICS, Washington DC.

[27] Felin, T. and Zenger, T.R. (2014) Closed or Open Innovation? Problem Solving and the Governance Choice. Research Policy, 43, 914-925. http://dx.doi.org/10.1016/j.respol.2013.09.006

[28] Portales-Trueba, C. (2002) Derecho Mercantil Mexicano. UACJ, Cd. Juárez. 
[29] Lanjouw, J.O. and Mody, A. (1996) Innovation and the International Diffusion of Environmentally Responsive Technology. Research Policy, 25, 549-571. http://dx.doi.org/10.1016/0048-7333(95)00853-5

[30] Zhu, X. (2013) Study on Natural Ecological Environment of Interior Design for Gyms. In: Wenjiang, D., Ed., Informatics and Management Science V, Springer, London, 567-574. http://dx.doi.org/10.1007/978-1-4471-4796-1_73

[31] Mussard, M. and Nydal, O.J. (2013) Charging of a Heat Storage Coupled with a Low-Cost Small-Scale Solar Parabolic Trough for Cooking Purposes. Solar Energy, 95, 144-154. http://dx.doi.org/10.1016/j.solener.2013.06.013

[32] Solar Energy for Homes (2010) How to Warm up Your Home Using Passive Solar Heating. http://www.solar-energy-for-homes.com/passive-solar-heating.html

[33] Pulselli, F.M., Coscieme, L. and Bastianoni, S. (2011) Ecosystem Services as a Counterpart of Emergy Flows to Ecosystems. Ecological Modelling, 222, 2924-2928. http://dx.doi.org/10.1016/j.ecolmodel.2011.04.022

[34] Bastianoni, S., Coscieme, L. and Pulselli, F.M. (2014) The Input-State-Output Model and Related Indicators to Investigate the Relationships among Environment, Society and Economy. Ecological Modelling. (in press) http://www.sciencedirect.com/science/article/pii/S0304380014004840 http://dx.doi.org/10.1016/j.ecolmodel.2014.10.015

[35] Del Pozo, R.P.P., De Melo, C.V. and Rodriguez, E.O. (2014) El análisis emergético como herramienta para evaluar la sustentabilidad en dos sistemas productivos. Ciencias Técnicas Agropecuarias, 23, 59-63.

[36] Izursa, A.J.L. (2011) Emergía (con M), una herramienta nueva para estimar el valor de la madera en el bosque. Ecología en Bolivia, 46, 71-76.

[37] Brown, M.T. (1999) Emergy Synthesis: Theory and Applications of the Emergy Methodology. http://www.cep.ees.ufl.edu/emergy/documents/conferences/ERC01_1999/ERC01_1999_Chapter_01.pdf

[38] Brown, M.T. and Ulgiati, S. (2004) Emergy Analysis and Environmental Accounting. Encyclopedia of Energy, 2, 329354. http://dx.doi.org/10.1016/B0-12-176480-X/00242-4

[39] Ulgiati, S., Raugei, M. and Bargigli, S. (2006) Overcoming the Inadequacy of Single-Criterion Approaches to Life Cycle Assessment. Ecological Modelling, 190, 432-442. http://dx.doi.org/10.1016/j.ecolmodel.2005.03.022

[40] United States Environmental Protection Agency (USEPA) (2014) Emission Factors for Greenhouse Gas Inventories. http://www.epa.gov/climateleadership/documents/emission-factors.pdf

[41] Bastianoni, S., Marchettini, N., Panzieri, M. and Tiezzi, E. (2001) Sustainability Assessment of a Farm in the Chianti Area (Italy). Journal of Cleaner Production, 9, 365-373. http://dx.doi.org/10.1016/S0959-6526(00)00079-2

[42] Brown, M.T. and Buranakarn, V. (2003) Emergy Indices and Ratios for Sustainable Material Cycles and Recycle Options. Resources Conservation \& Recycling, 38, 1-22. http://dx.doi.org/10.1016/S0921-3449(02)00093-9

[43] Ulgiati, S. and Brown, M.T. (2002) Quantifying the Environmental Support for Dilution and Abatement of Process Emissions: The Case of Electricity Production. Journal of Cleaner Production, 10, 321-334. http://dx.doi.org/10.1016/S0959-6526(01)00044-0

[44] Buenfil, A.A. (2001) Emergy Evaluation of Water. PhD Dissertation, University of Florida, Gainesville.

[45] Buranakarn, V. (1998) Evaluation of Recycling and Reuse of Building Materials Using the Emergy Analysis Method. PhD Dissertation, University of Florida, Gainesville.

[46] Haukoos, D.S. (1995) Sustainable Architeture and Its Relationship to Industrialized Building. Master Thesis, University of Florida, Gainesville.

[47] Lapp, C.W. (1991) Emergy Analysis of the Nuclear Power System in the United States. A Master’s Paper, University of Florida, Gainesville.

[48] Nelson, M., Odum, H.T., Brown, M.T. and Alling, A. (2001) Living off the Land: Resource Efficiency of Wetland Wastewater Treatment. Advances in Space Research, 27, 1547-1556. http://dx.doi.org/10.1016/S0273-1177(01)00246-0

[49] Paoli, C. and Vassallo, P. (2008) Solar Power: An Approach to Transformity Evaluation. Ecological Engineering, 34, 191-206. http://dx.doi.org/10.1016/j.ecoleng.2008.08.005 
Appendix A. Unit Emergy Values (UEV) considered in this work. Source: Own elaboration, adapted from various sources. [24] [41]-[49].

\begin{tabular}{|c|c|c|}
\hline Category and Item & Unit & seJ/Unit \\
\hline \multicolumn{3}{|l|}{ Materials } \\
\hline Wiring (copper) & g & 1.14E11 \\
\hline Plastic & g & $9.86 \mathrm{E} 9$ \\
\hline Circuit (copper) & g & $1.14 \mathrm{E} 11$ \\
\hline Electricity & $\mathrm{J}$ & $2.90 \mathrm{E} 5$ \\
\hline Reflector frame & g & 4.65E9 \\
\hline Ceramic far infrared emitter & g & $5,14 \mathrm{E} 9$ \\
\hline Metal far infrared emitter & g & 4.65E9 \\
\hline Carbon far infrared emitter & g & 4.65E9 \\
\hline Steel structure & g & 2.77E9 \\
\hline Pipeline (steel) & g & 2.77E9 \\
\hline Pipeline (copper) & g & $1.14 \mathrm{E} 11$ \\
\hline Mirror glass & g & $1.32 \mathrm{E} 10$ \\
\hline Aluminum & g & 2.74E 10 \\
\hline Aluminum concentrator & g & 4.65E9 \\
\hline Blowers & g & 4.65E9 \\
\hline Clay brick & g & $3.90 \mathrm{E} 9$ \\
\hline Cement & g & $6.40 \mathrm{E} 7$ \\
\hline Steel bars & g & 2.77E9 \\
\hline Wood pellets & g & $1.48 \mathrm{E} 9$ \\
\hline Wood & g & $6.79 \mathrm{E} 8$ \\
\hline Sauna stones & g & $1.00 \mathrm{E} 9$ \\
\hline Water & $\mathrm{m}^{3}$ & $2.25 \mathrm{E} 11$ \\
\hline Natural gas & $\mathrm{J}$ & $1.18 \mathrm{E} 5$ \\
\hline Gas tank (steel) & g & 2.77E9 \\
\hline Energy generation equipment & g & $1.90 \mathrm{E} 11$ \\
\hline \multicolumn{3}{|l|}{ Labor } \\
\hline Installation & $\mathrm{hr}$ & $2.14 \mathrm{E} 13$ \\
\hline Operation & $\mathrm{hr}$ & $2.14 \mathrm{E} 13$ \\
\hline Maintenance & $\mathrm{hr}$ & $2.14 \mathrm{E} 13$ \\
\hline \multicolumn{3}{|l|}{ Services } \\
\hline Materials cost & USD & 4.90E12 \\
\hline Installation & USD & $4.90 \mathrm{E} 12$ \\
\hline Operation & USD & $4.90 \mathrm{E} 12$ \\
\hline Maintenance & USD & $4.90 \mathrm{E} 12$ \\
\hline
\end{tabular}


Appendix B. Raw data for all 14 saunas assessed considering a 20-year lifetime. Source: Own elaboration. General observations: 1) renewable resources " $R$ " are water, rocks, and wool; all other items were assumed as economic resources "F"; none natural non-renewable resources "N" were identified in this study; 2) Services and labor have $2 \%$ of partial renewability (NEAD for Mexico in 2008); 3) Electricity has 8.8\% partial renewability according to [43]; 4) Electricity from photovoltaic panel has $2 \%$ partial renewability according to Paoli et al. (2008); 5) by definition, all other "R" resources have $100 \%$ of renewability; 6 ) all other "F" resources have $0 \%$ of partial renewability.

\begin{tabular}{|c|c|c|c|c|c|}
\hline Category and Item & Unit & $\begin{array}{c}\text { Fireplace } \\
\text { (from wood) }\end{array}$ & $\begin{array}{c}\text { Fresnel } \\
\text { (grid) }\end{array}$ & $\begin{array}{c}\text { Fresnel } \\
\text { (photovoltaic) }\end{array}$ & $\begin{array}{c}\text { Infrared ceramic } \\
\text { (grid) }\end{array}$ \\
\hline \multicolumn{6}{|l|}{ Materials } \\
\hline Wiring (cooper) & g & - & $2.14 \mathrm{E} 1$ & $2.14 \mathrm{E} 1$ & $1.43 \mathrm{E} 2$ \\
\hline Plastic & g & - & $2.18 \mathrm{E} 2$ & $2.18 \mathrm{E} 2$ & $2.18 \mathrm{E} 2$ \\
\hline Circuit (cooper) & g & - & 5.08E2 & $5.08 \mathrm{E} 2$ & $5.08 \mathrm{E} 2$ \\
\hline Electricity & $\mathrm{J}$ & - & $1.46 \mathrm{E} 11$ & $1.46 \mathrm{E} 11$ & $1.30 \mathrm{E} 12$ \\
\hline Reflector frame & g & - & - & - & 4.19E5 \\
\hline Ceramic far infrared emitter & g & - & - & - & $4.80 \mathrm{E} 5$ \\
\hline Metal far infrared emitter & g & - & - & - & - \\
\hline Carbon far infrared emitter & g & - & - & - & - \\
\hline Steel structure & g & - & $5.00 \mathrm{E} 3$ & $5.00 \mathrm{E} 3$ & - \\
\hline \multicolumn{6}{|l|}{ Pipeline (steel) } \\
\hline Pipeline (cooper) & g & - & 7.13E3 & 7.13E3 & - \\
\hline Mirror glass & g & - & $5.00 \mathrm{E} 3$ & $5.00 \mathrm{E} 3$ & - \\
\hline Aluminum & g & - & $1.00 \mathrm{E} 2$ & $1.00 \mathrm{E} 2$ & - \\
\hline Aluminum concentrator & g & - & $2.50 \mathrm{E} 3$ & $2.50 \mathrm{E} 3$ & - \\
\hline Blowers & g & - & $2.00 \mathrm{E} 2$ & $2.00 \mathrm{E} 2$ & - \\
\hline Clay brick & g & $2.10 \mathrm{E} 5$ & - & - & - \\
\hline Cement & g & $8.65 \mathrm{E} 5$ & - & - & - \\
\hline Steel bars & g & $1.01 \mathrm{E} 3$ & - & - & - \\
\hline Wood pellets & g & - & - & - & - \\
\hline Wood & g & 1.13E9 & - & - & - \\
\hline Sauna stones & g & $1.20 \mathrm{E} 5$ & $1.20 \mathrm{E} 5$ & $1.20 \mathrm{E} 5$ & - \\
\hline Water & $\mathrm{m}^{3}$ & $9.12 \mathrm{E} 1$ & $9.12 \mathrm{E} 1$ & $9.12 \mathrm{E} 1$ & - \\
\hline Natural gas & $\mathrm{J}$ & - & - & - & - \\
\hline Gas tank (steel) & g & - & - & - & - \\
\hline Energy generat. equipment & g & - & - & - & - \\
\hline \multicolumn{6}{|l|}{ Labor } \\
\hline Installation & $\mathrm{hr}$ & $8.00 \mathrm{E} 0$ & $3.00 \mathrm{E} 0$ & $3.00 \mathrm{E} 0$ & $2.40 \mathrm{E} 1$ \\
\hline Operation & $\mathrm{hr}$ & $1.12 \mathrm{E} 4$ & $1.12 \mathrm{E} 3$ & $1.12 \mathrm{E} 3$ & $5.60 \mathrm{E} 2$ \\
\hline Maintenance & $\mathrm{hr}$ & $1.12 \mathrm{E} 4$ & $1.20 \mathrm{E} 2$ & $1.20 \mathrm{E} 2$ & $1.20 \mathrm{E} 2$ \\
\hline \multicolumn{6}{|l|}{ Services } \\
\hline Materials cost & USD & $9.05 \mathrm{E} 4$ & 7.61E4 & $2.00 \mathrm{E} 4$ & 4.37E4 \\
\hline Installation & USD & $5.12 \mathrm{E} 0$ & $1.92 \mathrm{E} 0$ & $1.92 \mathrm{E} 0$ & $1.54 \mathrm{E} 1$ \\
\hline Operation & USD & $7.16 \mathrm{E} 3$ & 7.17E2 & 7.17E2 & $3.58 \mathrm{E} 2$ \\
\hline Maintenance & USD & $7.16 \mathrm{E} 3$ & $7.68 \mathrm{E} 1$ & $7.68 \mathrm{E} 1$ & $7.68 \mathrm{E} 1$ \\
\hline
\end{tabular}




\begin{tabular}{|c|c|c|c|c|c|}
\hline Category and Item & Unit & $\begin{array}{l}\text { Infrared ceramic } \\
\text { (photovoltaic) }\end{array}$ & $\begin{array}{l}\text { Infrared metal } \\
\text { (grid) }\end{array}$ & $\begin{array}{l}\text { Infrared metal } \\
\text { (photovoltaic) }\end{array}$ & $\begin{array}{c}\text { Infrared carbon } \\
\text { (grid) }\end{array}$ \\
\hline \multicolumn{6}{|l|}{ Materials } \\
\hline Wiring (cooper) & g & $1.43 \mathrm{E} 2$ & $1.43 \mathrm{E} 2$ & $1.43 \mathrm{E} 2$ & 1.43E2 \\
\hline Plastic & g & $2.18 \mathrm{E} 2$ & $2.18 \mathrm{E} 2$ & $2.18 \mathrm{E} 2$ & $2.18 \mathrm{E} 2$ \\
\hline Circuit (cooper) & g & $5.08 \mathrm{E} 2$ & $5.08 \mathrm{E} 2$ & $5.08 \mathrm{E} 2$ & $5.08 \mathrm{E} 2$ \\
\hline Electricity & $\mathrm{J}$ & 1.30E12 & $1.30 \mathrm{E} 12$ & $1.30 \mathrm{E} 12$ & 1.30E12 \\
\hline Reflector frame & g & 4.19E5 & 4.19E5 & 4.19E5 & 4.19E5 \\
\hline Ceramic far infrared emitter & g & $4.80 \mathrm{E} 5$ & - & - & - \\
\hline Metal far infrared emitter & g & - & $8.00 \mathrm{E} 5$ & $8.00 \mathrm{E} 5$ & - \\
\hline Carbon far infrared emitter & g & - & - & - & $6.00 \mathrm{E} 5$ \\
\hline Steel structure & g & - & - & - & - \\
\hline Pipeline (steel) & g & & & & \\
\hline Pipeline (cooper) & g & - & - & - & - \\
\hline Mirror glass & g & - & - & - & - \\
\hline Aluminum & g & - & - & - & - \\
\hline Aluminum concentrator & g & - & - & - & - \\
\hline Blowers & g & - & - & - & - \\
\hline Clay brick & g & - & - & - & - \\
\hline Cement & g & - & - & - & - \\
\hline Steel bars & g & - & - & - & - \\
\hline \multicolumn{6}{|l|}{ Wood pellets } \\
\hline Wood & g & - & - & - & - \\
\hline Sauna stones & g & - & - & - & - \\
\hline Water & $\mathrm{m}^{3}$ & - & - & - & - \\
\hline Natural gas & $\mathrm{J}$ & - & - & - & - \\
\hline Gas tank (steel) & g & - & - & - & - \\
\hline Energy generat. equipment & g & - & - & - & - \\
\hline \multicolumn{6}{|l|}{ Labor } \\
\hline Installation & $\mathrm{hr}$ & $2.40 \mathrm{E} 1$ & $2.40 \mathrm{E} 1$ & $2.40 \mathrm{E} 1$ & $2.40 \mathrm{E} 1$ \\
\hline Operation & $\mathrm{hr}$ & $5.60 \mathrm{E} 2$ & $5.60 \mathrm{E} 2$ & $5.60 \mathrm{E} 2$ & $5.60 \mathrm{E} 2$ \\
\hline Maintenance & $\mathrm{hr}$ & $1.20 \mathrm{E} 2$ & $1.20 \mathrm{E} 2$ & $1.20 \mathrm{E} 2$ & $1.20 \mathrm{E} 2$ \\
\hline \multicolumn{6}{|l|}{ Services } \\
\hline Materials cost & USD & $4.97 \mathrm{E} 3$ & $4.37 \mathrm{E} 4$ & $4.37 \mathrm{E} 4$ & 4.37E4 \\
\hline Installation & USD & $1.54 \mathrm{E} 1$ & $1.54 \mathrm{E} 1$ & $1.54 \mathrm{E} 1$ & $1.54 \mathrm{E} 1$ \\
\hline Operation & USD & 3.58E2 & $3.58 \mathrm{E} 2$ & 3.58E2 & 3.58E2 \\
\hline Maintenance & USD & $7.68 \mathrm{E} 1$ & $7.68 \mathrm{E} 1$ & 7.68E1 & $7.68 \mathrm{E} 1$ \\
\hline
\end{tabular}




\begin{tabular}{|c|c|c|c|c|c|}
\hline Category and Item & Unit & $\begin{array}{l}\text { Infrared carbon } \\
\text { (photovoltaic) }\end{array}$ & $\begin{array}{c}\text { Heater } \\
\text { (fireplace) }\end{array}$ & Heater (pellets) & Heater (gas) \\
\hline \multicolumn{6}{|l|}{ Materials } \\
\hline Wiring (cooper) & g & $1.43 \mathrm{E} 2$ & - & - & - \\
\hline Plastic & g & $2.18 \mathrm{E} 2$ & $3.00 \mathrm{E} 4$ & $2.18 \mathrm{E} 2$ & $2.18 \mathrm{E} 2$ \\
\hline Circuit (cooper) & g & $5.08 \mathrm{E} 2$ & $1.14 \mathrm{E} 5$ & $5.08 \mathrm{E} 2$ & $5.08 \mathrm{E} 2$ \\
\hline Electricity & $\mathrm{J}$ & $1.30 \mathrm{E} 12$ & - & - & - \\
\hline Reflector frame & g & 4.19E5 & - & - & - \\
\hline Ceramic far infrared emitter & g & - & - & - & - \\
\hline Metal far infrared emitter & g & - & - & - & - \\
\hline Carbon far infrared emitter & g & $6.00 \mathrm{E} 5$ & - & - & - \\
\hline Steel structure & g & - & $3.00 \mathrm{E} 4$ & $3.00 \mathrm{E} 4$ & $1.30 \mathrm{E} 6$ \\
\hline Pipeline (steel) & g & - & $1.14 \mathrm{E} 5$ & $1.14 \mathrm{E} 5$ & $1.14 \mathrm{E} 5$ \\
\hline Pipeline (cooper) & g & - & - & - & $3.76 \mathrm{E} 3$ \\
\hline Mirror glass & g & - & - & - & - \\
\hline Aluminum & g & - & - & - & - \\
\hline Aluminum concentrator & g & - & - & - & - \\
\hline Blowers & g & - & - & - & - \\
\hline Clay brick & g & - & - & - & - \\
\hline Cement & g & - & - & - & - \\
\hline Steel bars & g & - & - & - & - \\
\hline Wood pellets & g & - & & $1.40 \mathrm{E} 7$ & - \\
\hline Wood & g & - & $5.08 \mathrm{E} 2$ & - & - \\
\hline Sauna stones & g & - & $1.20 \mathrm{E} 5$ & $1.20 \mathrm{E} 5$ & $1.20 \mathrm{E} 5$ \\
\hline Water & $\mathrm{m}^{3}$ & - & $9.12 \mathrm{E} 1$ & $9.12 \mathrm{E} 1$ & $9.12 \mathrm{E} 1$ \\
\hline Natural gas & $\mathrm{J}$ & - & - & - & 2.17E14 \\
\hline Gas tank (steel) & g & - & - & - & $4.42 \mathrm{E} 6$ \\
\hline Energy generat. equipment & g & - & - & - & - \\
\hline \multicolumn{6}{|l|}{ Labor } \\
\hline Installation & $\mathrm{hr}$ & $2.40 \mathrm{E} 1$ & $3.00 \mathrm{E} 0$ & $3.00 \mathrm{E} 0$ & $3.00 \mathrm{E} 0$ \\
\hline Operation & $\mathrm{hr}$ & $5.60 \mathrm{E} 2$ & $1.12 \mathrm{E} 4$ & $1.12 \mathrm{E} 4$ & $2.80 \mathrm{E} 1$ \\
\hline Maintenance & $\mathrm{hr}$ & $1.20 \mathrm{E} 2$ & $1.12 \mathrm{E} 4$ & $1.12 \mathrm{E} 4$ & $6.00 \mathrm{E} 0$ \\
\hline \multicolumn{6}{|l|}{ Services } \\
\hline Materials cost & USD & $4.97 \mathrm{E} 3$ & $4.30 \mathrm{E} 4$ & $1.13 \mathrm{E} 4$ & 4.63E4 \\
\hline Installation & USD & $1.54 \mathrm{E} 1$ & $1.92 \mathrm{E} 0$ & $1.92 \mathrm{E} 0$ & $1.92 \mathrm{E} 0$ \\
\hline Operation & USD & $3.58 \mathrm{E} 2$ & 7.17E3 & 7.17E3 & $1.79 \mathrm{E} 1$ \\
\hline Maintenance & USD & $7.68 \mathrm{E} 1$ & 7.17E3 & 7.17E3 & $3.84 \mathrm{E} 0$ \\
\hline
\end{tabular}




\begin{tabular}{|c|c|c|c|c|c|}
\hline Category and Item & Unit & Heater (grid) & $\begin{array}{c}\text { Heater } \\
\text { (photovoltaic) }\end{array}$ & - & - \\
\hline \multicolumn{6}{|l|}{ Materials } \\
\hline Wiring (cooper) & g & $6.42 \mathrm{E} 0$ & $6.42 \mathrm{E} 0$ & - & - \\
\hline Plastic & g & 4.35E2 & $2.18 \mathrm{E} 2$ & - & - \\
\hline Circuit (cooper) & g & $1.02 \mathrm{E} 3$ & $5.08 \mathrm{E} 2$ & - & - \\
\hline Electricity & $\mathrm{J}$ & 3.15E12 & 3.15E12 & - & - \\
\hline Reflector frame & g & - & - & - & - \\
\hline Ceramic far infrared emitter & g & - & - & - & - \\
\hline Metal far infrared emitter & g & - & - & - & - \\
\hline Carbon far infrared emitter & g & - & - & - & - \\
\hline Steel structure & g & $8.27 \mathrm{E} 3$ & $4.14 \mathrm{E} 3$ & & \\
\hline Pipeline (steel) & g & - & - & - & - \\
\hline Pipeline (cooper) & g & - & - & - & - \\
\hline Mirror glass & g & - & - & - & - \\
\hline Aluminum & g & - & - & - & - \\
\hline Aluminum concentrator & g & - & - & - & - \\
\hline Blowers & g & - & - & - & - \\
\hline Clay brick & g & - & - & - & - \\
\hline Cement & g & - & - & - & - \\
\hline Steel bars & g & - & - & - & - \\
\hline Wood pellets & g & - & - & - & - \\
\hline Wood & g & - & - & - & - \\
\hline Sauna stones & g & $1.20 \mathrm{E} 5$ & $1.20 \mathrm{E} 5$ & - & - \\
\hline Water & $\mathrm{m}^{3}$ & $9.12 \mathrm{E} 1$ & $9.12 \mathrm{E} 1$ & - & - \\
\hline Natural gas & $\mathrm{J}$ & - & - & - & - \\
\hline Gas tank (steel) & g & - & - & - & - \\
\hline Energy generat. equipment & g & $1.93 \mathrm{E} 4$ & $9.56 \mathrm{E} 3$ & - & - \\
\hline \multicolumn{6}{|l|}{ Labor } \\
\hline Installation & $\mathrm{hr}$ & $3.00 \mathrm{E} 0$ & $3.00 \mathrm{E} 0$ & - & - \\
\hline Operation & $\mathrm{hr}$ & $5.60 \mathrm{E} 2$ & $5.60 \mathrm{E} 2$ & - & - \\
\hline Maintenance & $\mathrm{hr}$ & $1.20 \mathrm{E} 2$ & $1.20 \mathrm{E} 2$ & - & - \\
\hline \multicolumn{6}{|l|}{ Services } \\
\hline Materials cost & USD & 2.03E5 & $7.85 \mathrm{E} 4$ & - & - \\
\hline Installation & USD & $1.92 \mathrm{E} 0$ & $1.92 \mathrm{E} 0$ & - & - \\
\hline Operation & USD & $3.58 \mathrm{E} 2$ & $3.58 \mathrm{E} 2$ & - & - \\
\hline Maintenance & USD & $7.68 \mathrm{E} 1$ & $7.68 \mathrm{E} 1$ & - & - \\
\hline
\end{tabular}

